\title{
EFFECTS OF JUNE WINDS ON RAINFALL IN THE COASTAL REGION OF KENYA
}

Muti SM${ }^{1 *}$ and W Ng'etich ${ }^{2}$

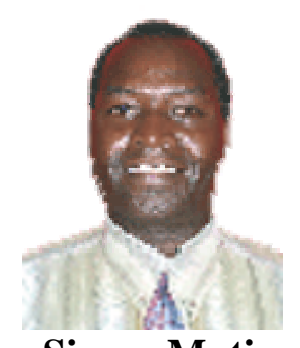

Simon Muti

*Corresponding author email: mutisimon@yahoo.co.uk

${ }^{1}$ Department of Agriculture, Pwani University College, P.O. Box 195, Kilifi, Kenya

${ }^{2}$ Department of Soil Sciences, Moi University, P.O. Box 1125, Eldoret, Kenya 


\begin{abstract}
Although the equatorial Eastern region of Africa is adjacent to the Indian Ocean, it tends to exhibit a drier climate rather than one characterized by abundant tropical rains. A number of studies on rainfall variability in the East African region have tended to suggest a stronger influence of local factors in controlling rainfall amounts and their characteristics rather than the global wind circulation system. A climatic phenomenon that is locally termed "June winds" is unique to East Africa's coastal region. The study mainly involved analysing rainfall anomalies and means of 39- year meteorological data from the region and data from earlier studies about the region. The results indicate that June winds occur annually after the onset of long rains between the months of May and June. They impart subsidence, drying and cloud free conditions, altering the climatological properties in the areas they traverse. The attainment of peak June wind velocities causes a characteristic depression in rainfall probability and amounts on their course, similar to the 'Ganges depression' of temperatures in the Indian subcontinent, which in turn affects available soil moisture for crop growth. The results also reveal existence of years of "above-normal rains" (herein referred to as El Niño years) and years of "below-normal rains" (herein referred to as La Niña years) which are associated and modulated by El Niño southern oscillation. They also reveal that drought years tend to occur in succession and that the June winds tend to be suppressed or absent during El Niño years, but strongly associate with La Niña years. The study suggests that the frequency and therefore the ratio of La Niña years to El Niño years have been increasing. The study also suggests possibility of developing a decision support system for farmers in resource use and allocation based predicted time of occurrence of the June winds.
\end{abstract}

Key words: Low level, Jet, Rainfall, Kenya 


\section{INTRODUCTION}

Climate sets the environmental limits for agricultural production and determines the types of agricultural activities in different regions of the world. This is particularly true in lowland tropical areas of the developing world where rainfall amounts and the distribution of rainfall are the most important factors governing crop yields [1].

Most of the countries bordering large oceans and proximate to the equator, experience equatorial type of climate characterised by high average annual rainfall of over $2500 \mathrm{~mm}$, high relative humidity, dense equatorial forests and high yields of both food and tree crops[1]. Although East Africa is situated within the equatorial region $\left(10^{\circ} \mathrm{S}\right.$ $15^{\circ} \mathrm{N}$ ) adjacent to the warm Indian Ocean, the region has exceptionally low rainfall, complicated distribution and wide variability [2]. The high rainfall variability suggests a stronger influence and dominance of local factors in modulating the rainfall amounts and characteristics rather than the large-scale global wind circulation system [3]. Thus, even though the Coastal region of Kenya is adjacent to the Indian ocean and endowed with enormous agricultural potential of over $3700 \mathrm{~km}^{2}$ of good arable land and sandy-loam to clay loam soils, the rainfall tends to be erratic and unreliable [4].

Given that rains occur as a result of moisture and energy transfer by global wind systems, and that every ocean has its own wind systems, the factors that influence wind systems in a given region equally affect the amounts of rainfall received and its distribution, and consequently crop yields [5]. Persistent at the Coast and parts of Eastern Kenya, unlike other regions is the influence of high ambient temperatures and high velocity June winds (that part of the East African low level jet that manages to penetrate through the coastal ranges barrier into mainland East Africa)whose occurrence results in decrease in rainfall amounts.

Given that recent studies point towards increasing frequencies of periods of drier than normal (La Niña) years and that most drought periods tend to occur in succession of 2-3 years, the frequency of abortive seasons or crop failures are likely to increase, rendering the bulk of the Coastal and Eastern African population dependent on relief food [6].

However, the East African low level jet brings with it mixed results based on its course and destination. In Madagascar and South-western Indian sub-continent, the jet brings enormous amounts of rains while in the eastern horn of Africa, including Kenya through Somalia to Djibouti and the Arabian Peninsula, it causes cloud free conditions and 'abrupt drought conditions'. However, they reportedly cause some rains on the southern Ethiopian highlands [1].

This study was conducted to investigate the occurrence of June winds and their effects on rainfall in the Coastal and Eastern regions of Kenya. 


\section{MATERIALS AND METHODS}

\section{The study area}

The study centred on the lowland Coastal region of Kenya, located between $38.5^{\circ} \mathrm{E}$ and $41.5^{\circ} \mathrm{E}$ between $0^{\circ}$ and $5^{\circ} \mathrm{S}$ and stretching from Kwale district in the south through Mombasa, Kilifi, Malindi and Lamu districts to the north (Fig 1). Annual average temperatures ranged maximum $28-31^{\circ} \mathrm{C}$, and minimum, $20-23^{\circ} \mathrm{C}$. Long-term annual average rainfall is $1200 \mathrm{~mm}$ [4].

\section{Procedure}

The study involved analysis of 39- year records of rainfall data (1961-2000), wind run and data from baseline surveys in the region. Meteorological data from Malindi weather station was chosen to be representative of the study region because Malindi district is mid-way the study area. Analysis involved deriving rainfall anomalies over the entire period and comparison of the respective means and rainfall patterns with respect to wind runs during long rains season. 

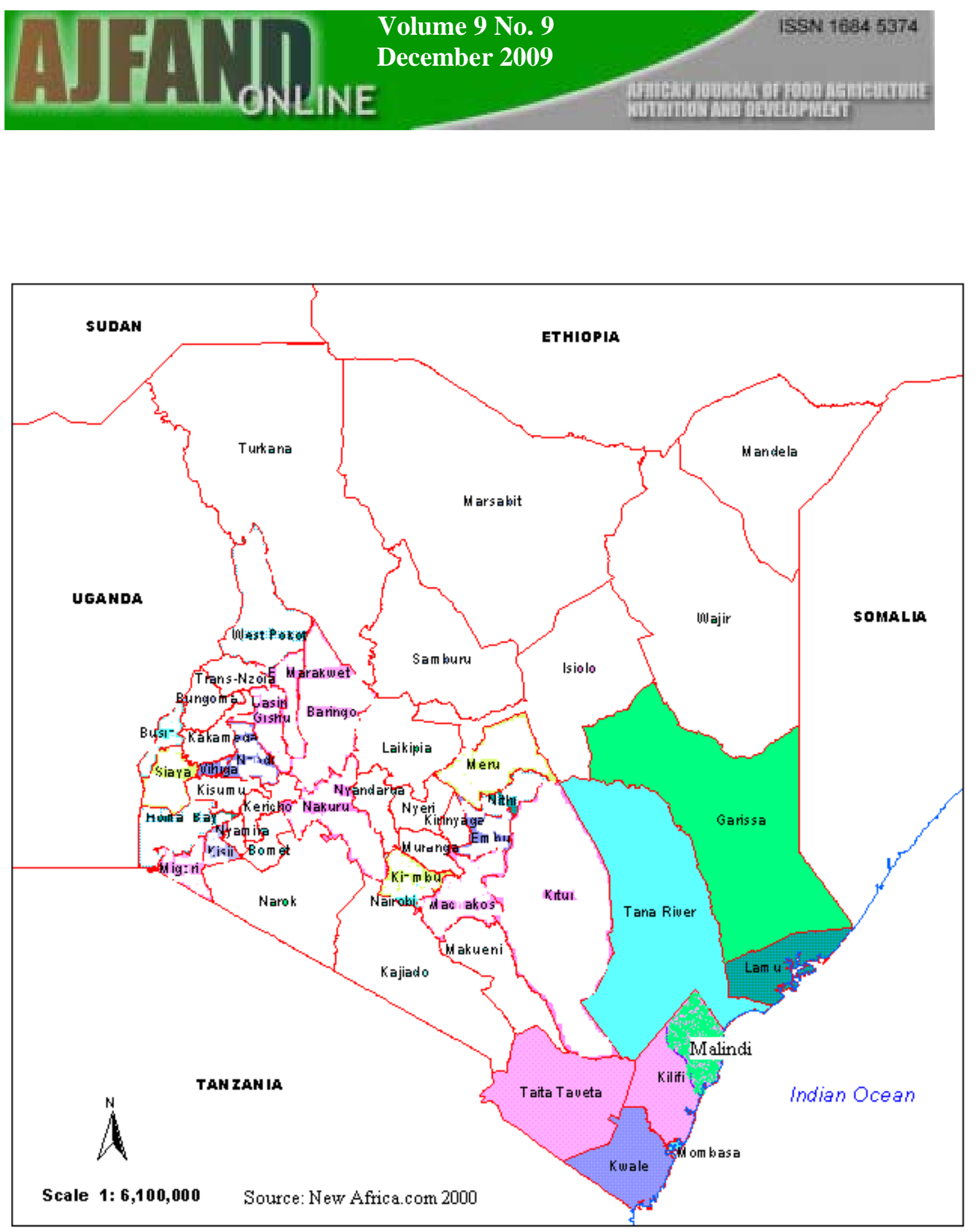

Figure 1: Map of the study area, Coastal region of Kenya 


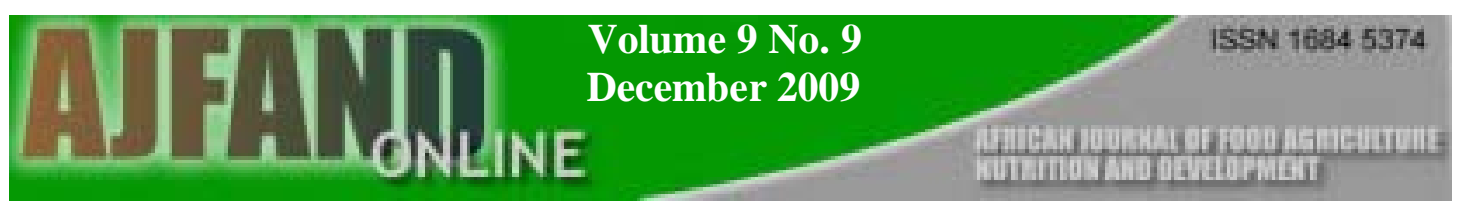

\section{RESULTS}

Monthly rainfall distribution and Potential evaporation in the region

Results in Fig. 2 show the annual rainfall pattern in the region. They indicate that the region experiences bimodal rainfall with at least some precipitation in most months of the year.

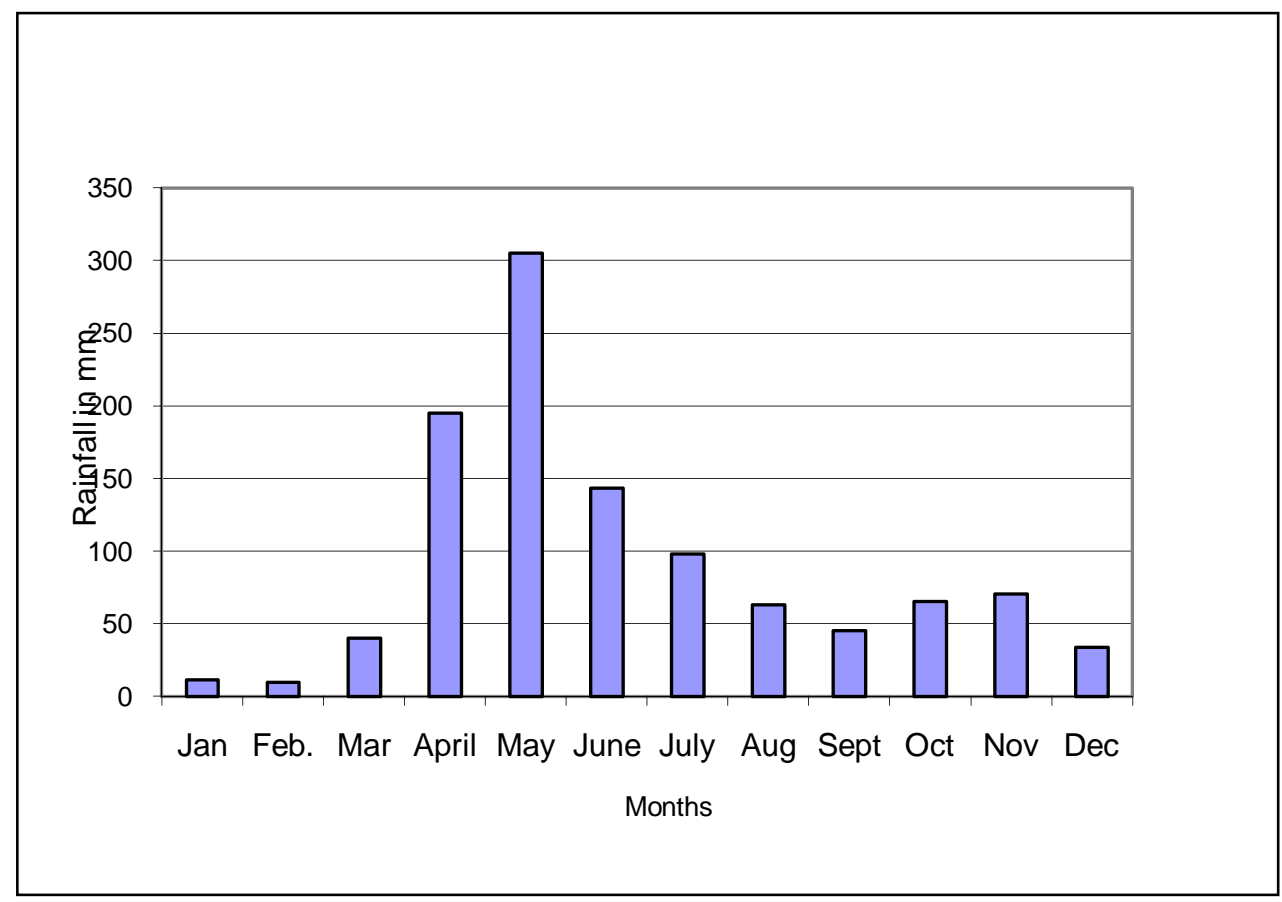

Figure 2: Mean annual rainfall pattern in Malindi

Table 1 shows the mean monthly rainfall and the potential evapo-transpiration for the region. From the table, it is evident that in a whole year, only two months experience positive moisture regime for crop growth, namely April and May which fall within the long rains season. In all other months, the potential evaporation exceeds received rainfall, implying deficit soil moisture situation for most of the year, reflecting a constraint in crop production in the region.

Figs 3 and 9 show the length of growing season for annual crops if we consider $50 \%$ (0.5 Eo) and $100 \%$ (Eo) potential evaporation under rain-fed conditions. They indicate that annual crops cultivation is possible from early to mid April when appreciable rains have been received to offset at least $50 \%$ potential evaporation and continues up to late July. 

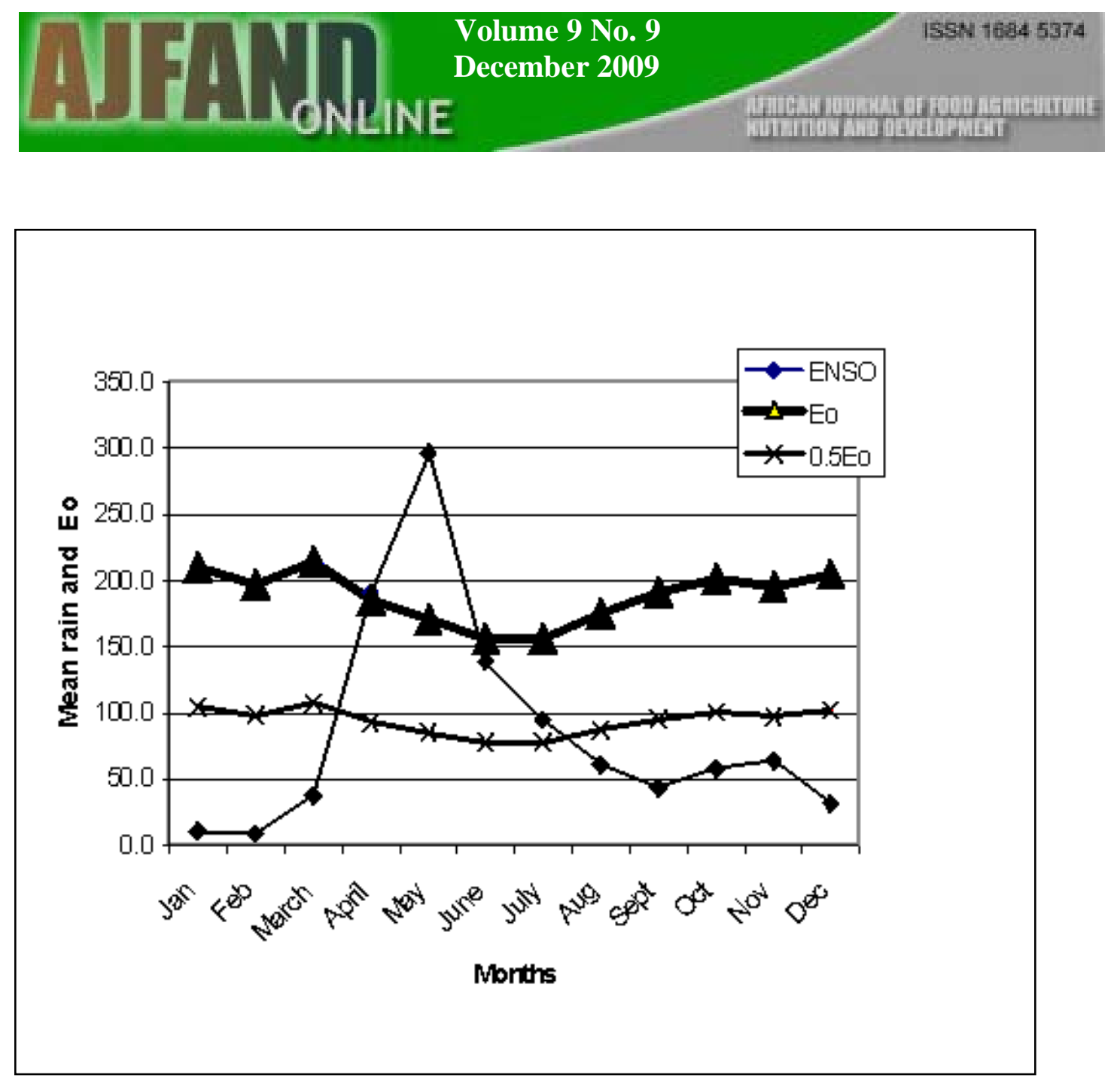

Figure 3: Definition of a growing season in Malindi

Fig. 4 shows probability of a rainy day in the region. It reveals that after peak long rains in early May, the probability of a rainy day and amounts suddenly dips to a low (marked X) mid-way between the months of May and June. It then increases between June and July before finally decreasing to a minimum at the end of the long rains season in late July-August. 

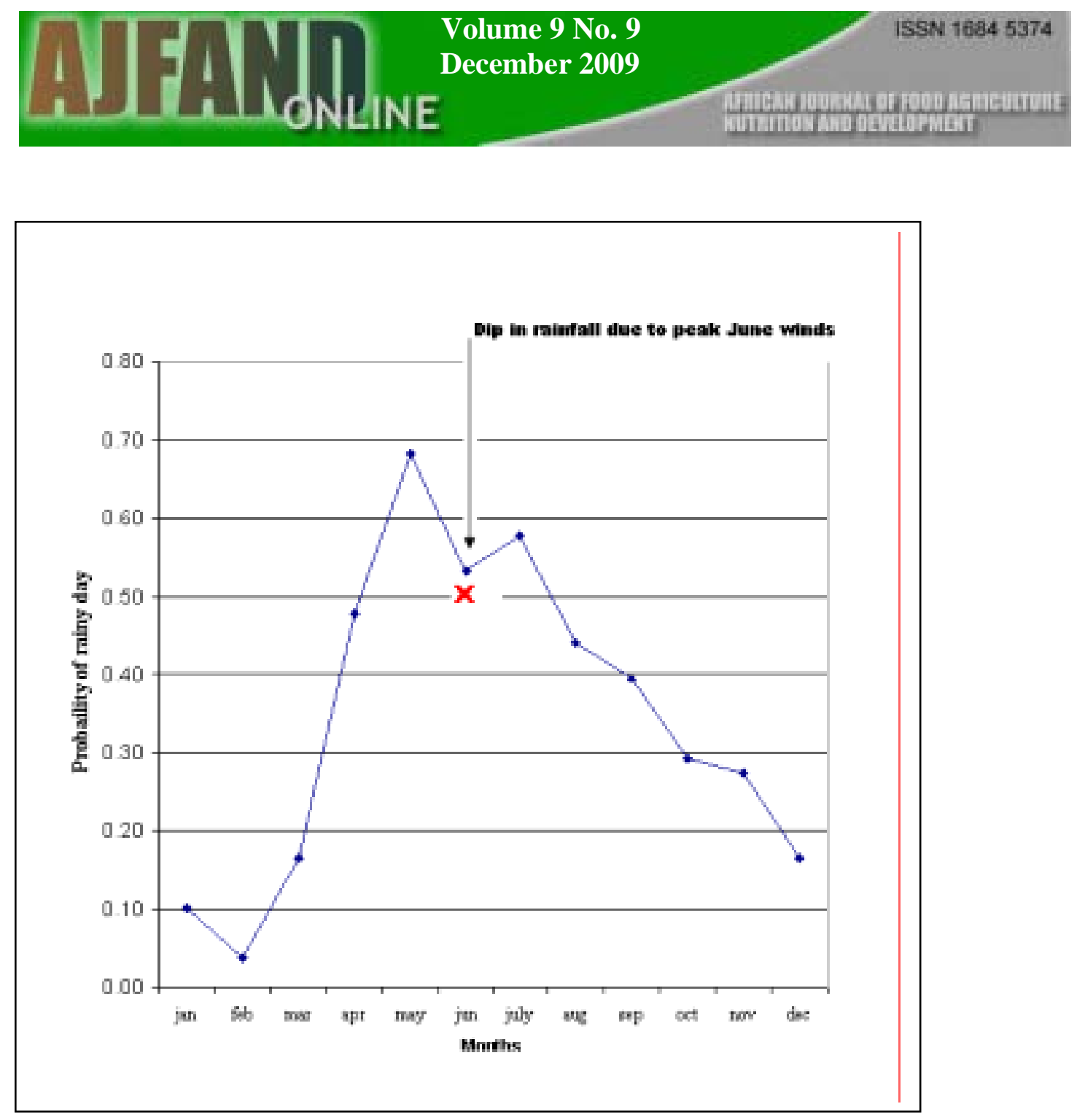

Figure 4: Probability of a rainy day in Malindi

Fig. 5 shows that the long rains season monthly wind speed reaches a peak in the month of June. 

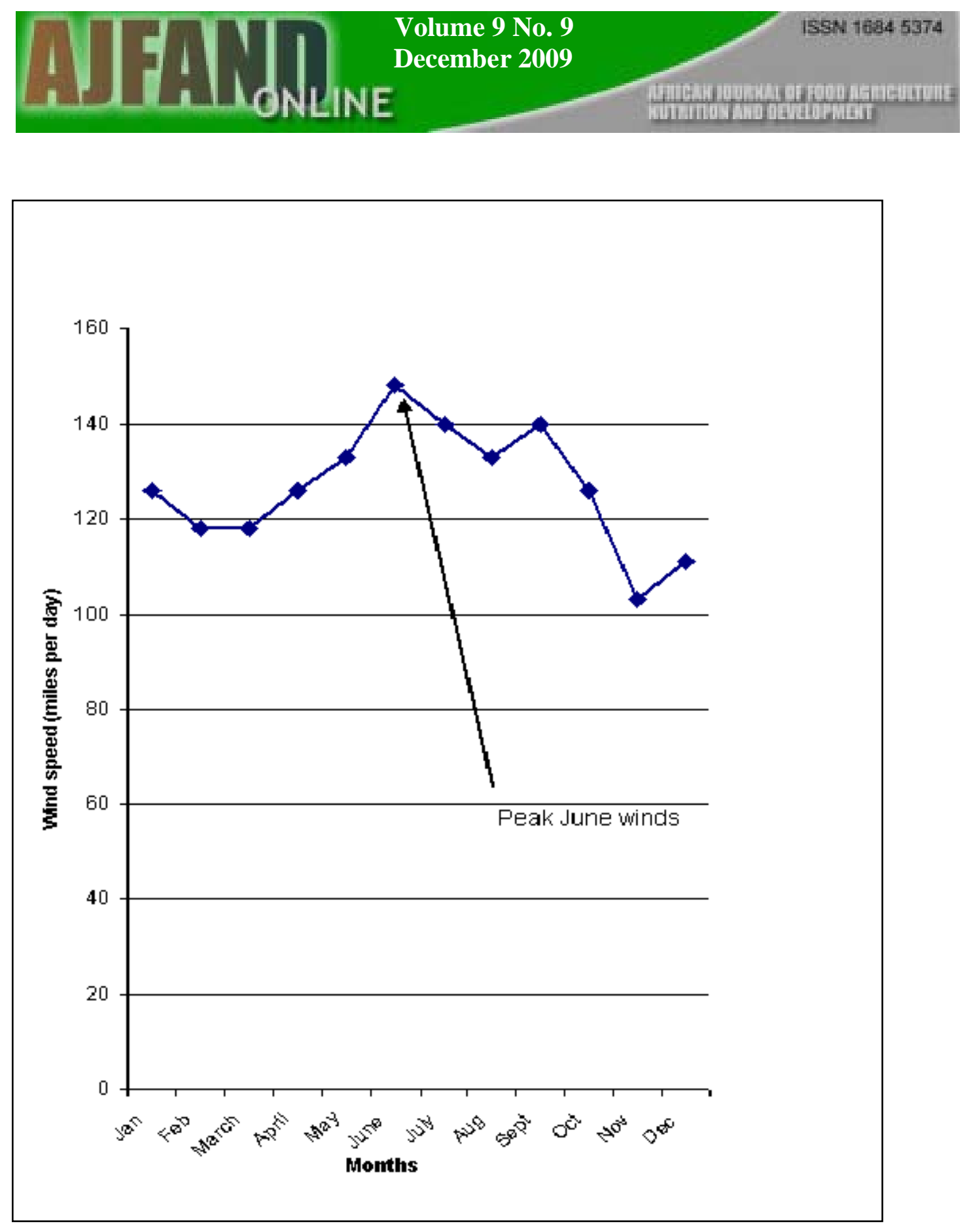

Figure 5: Monthly wind speed variation

Fig. 6 is a composite chart linking the monthly rainfall balances during the year (Fig. 6a), the rainfall probability (Fig. 6b) and monthly wind speed (Fig. 6c). 
(6a)

(6b)

$(6 c)$

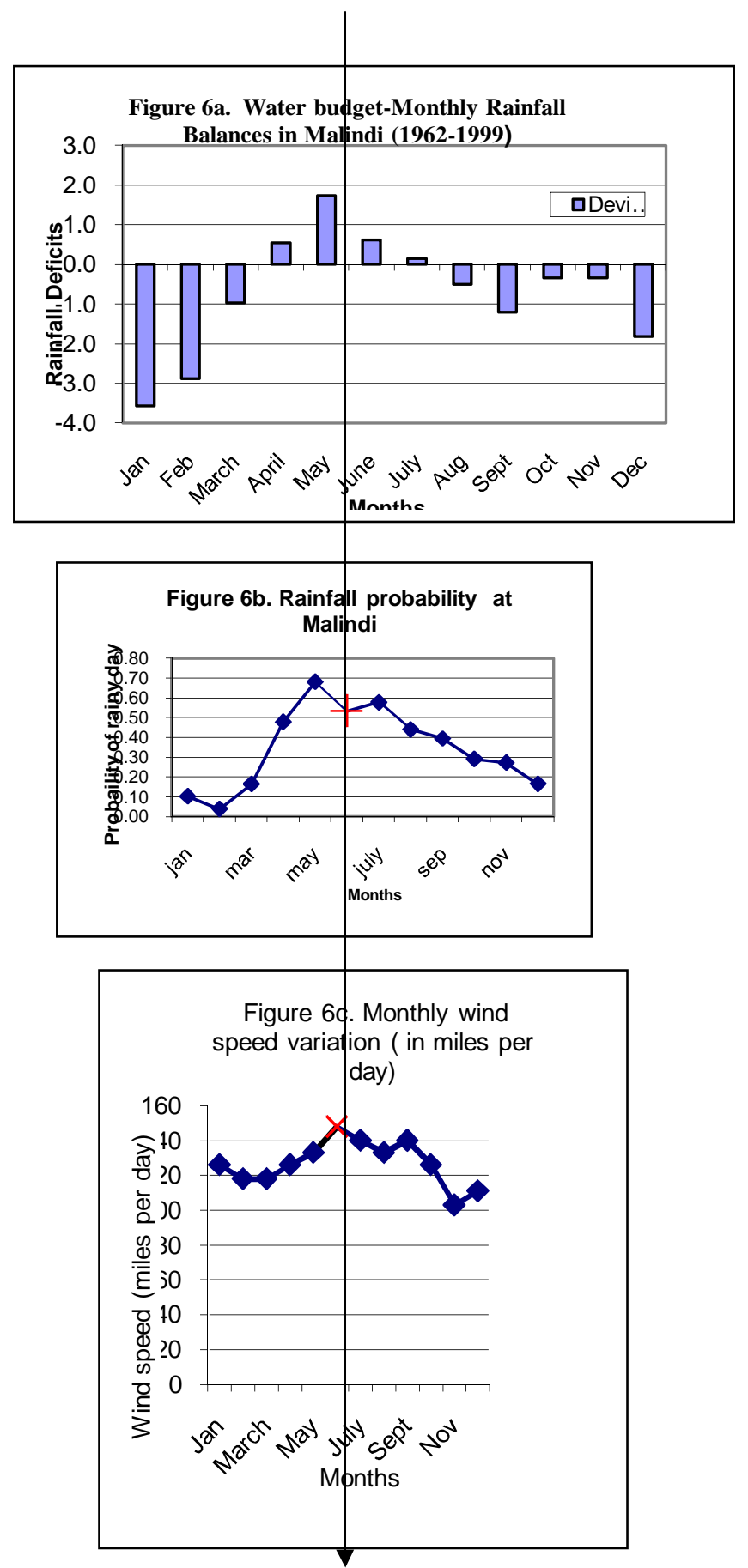

Figure 6: Coincidence of Peak June wind speeds and decline in rainfall probability

Note: the top-bottom arrow connects timing of June winds occurrence with other variables 

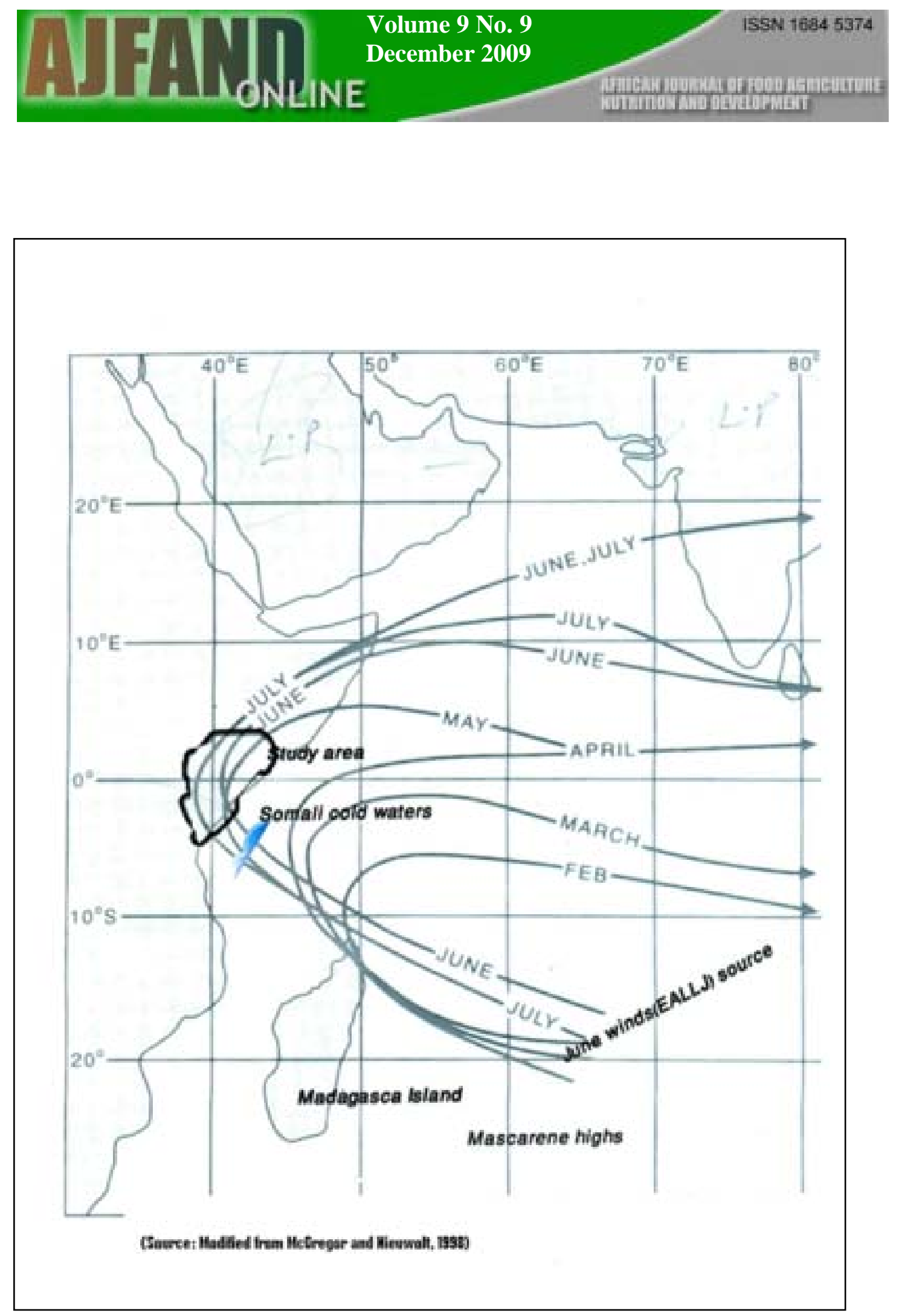

Figure 7: Annual progression of East African Low level Jet (June winds)

Fig. 7 shows the respective positions of the June winds during the months of a year.

Fig. 8 shows rainfall anomalies over the last 29 years and it is evident that from 1976 the frequency of drought (La Niña) years has been increasing compared to that of 
above normal rainfall years and that drought years occur in succession. Also a year of above normal rains (El Niño) tends to be followed by a severe drought.

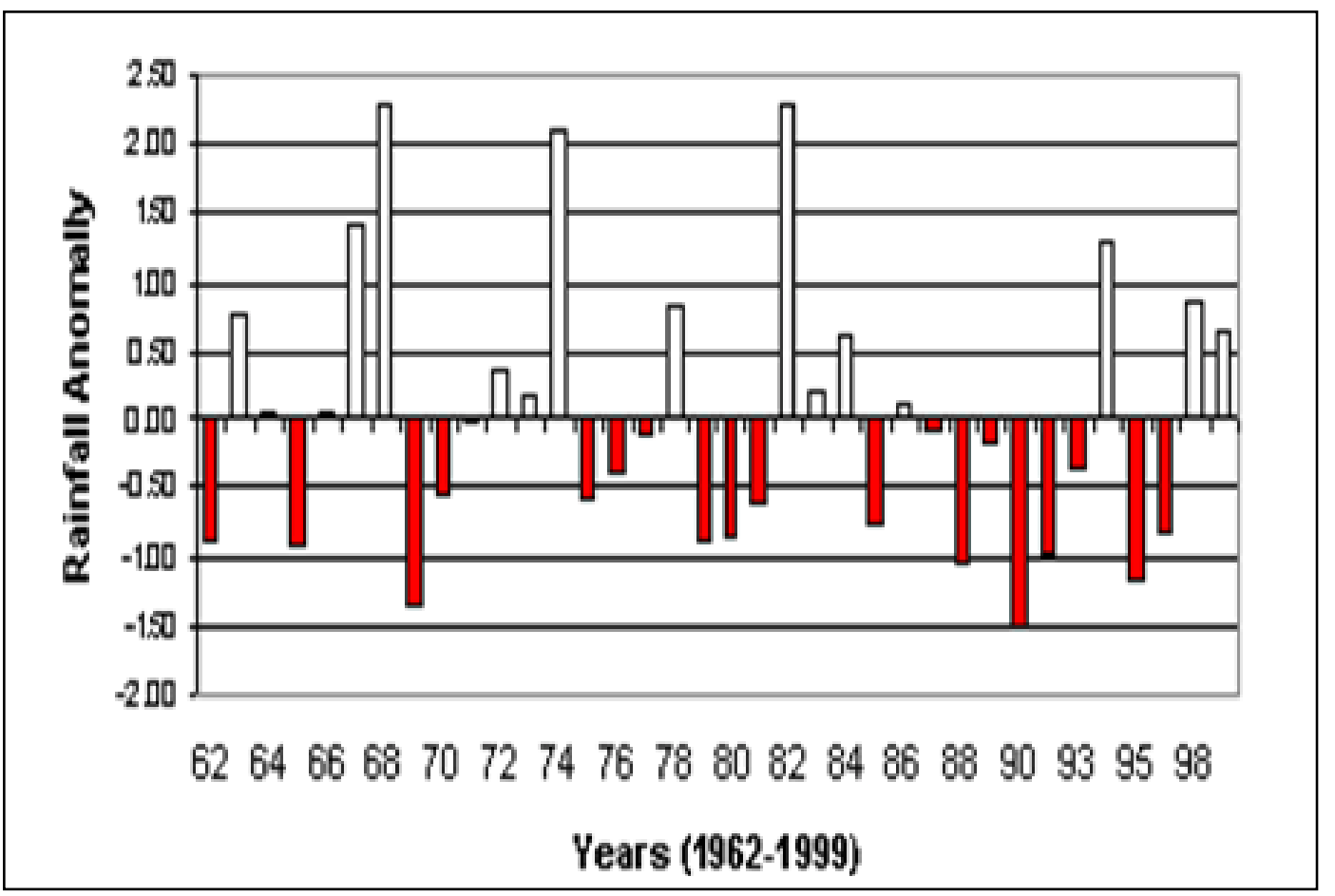

\section{Figure 8: Rainfall anomalies in Malindi}

Note: Drought (La Niña) years (Red bars) occur in succession of 2-3 years; An El Niño year is followed more often by dry years.

Fig. 9 shows average annual rainfall pattern during El Niño and La Niña years. It reveals that during the years of El Niño rains, the rains onset is early in the season and persists for long. However, in La Niña years, they come late and withdraw early. 

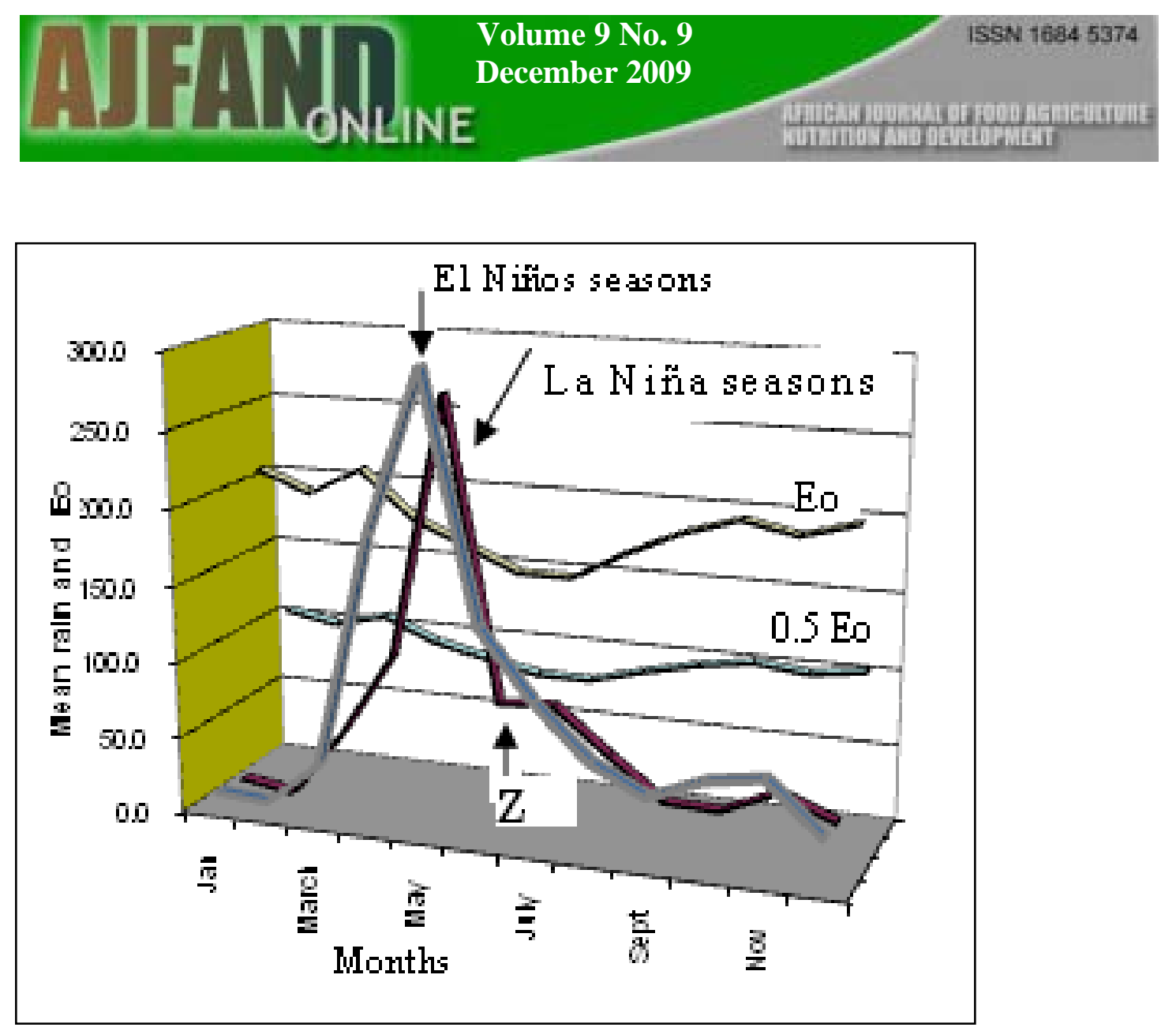

Figure 9: Start and end of rains during El Niño and La Niña years

Note: the triangle $(Z)$ denotes decline in rainfall due to occurrence of June winds in La Niña years 


\section{DISCUSSION}

\section{Rainfall characteristics in the study area}

Fig. 2 indicates that the region experienced bimodal rainfall with at least some precipitation in most months of the year. Rainfall in the region is occasioned by presence of the moisture laden South Easterlies and the North Westerlies. The sea surface temperature (SST) experienced by each ocean defines the general wind circulation systems that influence precipitation patterns and seasons in the adjacent mainland regions $[1,4,5]$. In the adjacent Indian Ocean, the South-easterlies bring the highest amount of moisture into the region (Fig. 2) having had a long distance of fetch, accounting for the highest proportion of the annual precipitation received in the region [3]. The North-easterlies contribute highest amounts during the short rains season (Fig. 2), the low amounts received during this time of the year being attributed to their course of journey having passed over the dry Arabian Peninsula and also being parallel to the coast line, with minimal fetch of moisture [7].

Figs. 2, 3 and Table 1 indicate that even though the area experiences bimodal rainfall, the short rains are much lower and cannot sustain an annual crop, especially maize, to maturity. Only two months in a year, namely April and May experience positive moisture relations, since in all other months potential evaporation exceeds received precipitation (Table 1). This has severe implications for crop growth in that much of the received rains and therefore soil moisture evaporate long before the crop can attain maturity or produce yield.

\section{The Interaction of June winds occurrence and rainfall}

Fig. 6, a composite chart revealed that as the June wind speeds approached their peak, the probability of rainfall decreased to a dip (marked X). This coincidence of decrease in rainfall amounts and probability with attainment of peak June wind speed suggests an interaction and that the winds are responsible for the decrease in rains during this time of growing season. A 5 day average wind run data (not shown) indicated that this peak lasted 7 to 10 days during the long rains season and occurred after the onset of long rains. Indeed a look at rainfall data from other spatially distributed weather recording stations in region, Table 2 confirms this depression in rainfall amounts and probability where the June winds traverse, reminiscent of the 'Ganges' temperature depressions in India. However, these depressions were also evident in months of May and July in certain years. The magnitude of the depressions in the different weather recording stations decreased towards the hinterlands as the amounts of rainfall also decreased, probably due to weakening of June winds intensities as topographic barriers increase. These depressions also reflect spatial and temporal variation in June winds occurrence relative to their progression through the expansive area and respective weather recording stations (Table 3 ).

\section{June winds-Origin and geographical extent}

A detailed account of origin and region of influence of the East African low level Jet stream is shown in Fig.7 [1, 8]. The winds are thermal winds and a creation of the onset and attainment of peak northern summer monsoon. The 39- year rainfall records

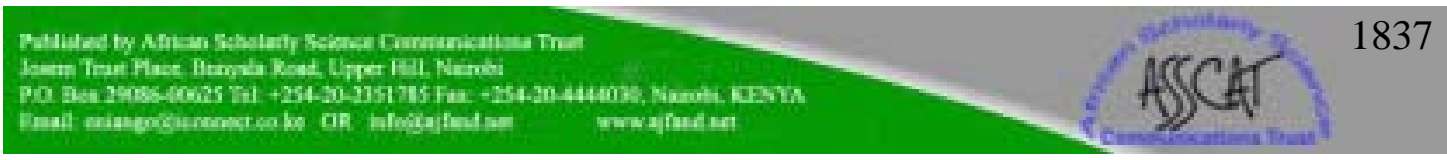


show that the June winds revisit parts of the East African Coast every year but for most part of the year, they maintain their presence located off-shore in the southwestern Indian Ocean confined to areas south of equator, mainly east of Madagascar during winter. Fig. 7 shows that they enter on-shore in an area in the vicinity of Mombasa and stretching along the coastal belt up to Garissa into Somali and Eastern horn of Africa. The jet exhibits progressive northward movement as the South-westerlies dominate over North-easterlies. Indeed the jet's path appears to coincide with the zone of convergence of South-westerlies and North-easterlies, the Inter-tropical Convergence Zone (ITCZ) and it can, thus, be described as a resultant jet of the two trade winds, analogous to a counter-current commonly observed in oceans when two water currents flow in the same directions [1].

Available wind run data (not shown) indicate that these winds during the 1-2 week presence in the study region occur in form of sustained bursts and gusts of high velocity strong winds, which sometimes result in lodging of tall maize crop.

\section{June winds and their climatological properties}

Figs. 4, 5 and 6 show that when June winds come, as they attain their maximum velocities they occasion a decrease in rainfall probability and amounts which most likely also causes a decline in soil moisture (Fig. 4, dip X). On their journey towards the equator, the Jet obtain their cool and adiabatically drying climatological conditions as they traverse over the cold upwelling Somali waters (Fig.7) [1].

As they move inland over the Coastal and Eastern regions of Kenya, they impart subsidence and cool weather conditions. Subsidence is responsible for the "drying effects" and "chasing away" any potential rains and enhancing cloud free conditions. It alters the properties of the troposphere and regions of deep convective activity, whereby the atmospheric air temperature tends to increase with height, preventing any condensation and cloud formation. This explains the decrease in rainfall amounts and probability in the study area (Fig. 4). More often, this tends to occur in the middle of long rains growing season, resulting in either splitting or shortening of the growing season. Indeed rainfall data of hinterland locations indicate that rainfall amounts decrease with distance from the coast into hinterland (Table 3), and that the occurrence of June winds more often signals termination of long rains and, therefore, end of the growing season. In Fig. 9 the triangle (marked $\mathrm{Z}$ ) indicates the magnitude of decrease in rainfall amounts and ranges between $50-100 \mathrm{~mm}$ in 1 to 2 weeks, due to effects of June winds occurrence during La Niña years compared to El Niño years when the June's winds effects are suppressed.

The moderating cooling effects of the cool upwelling Somali waters on the overflying East African low level jet as they approach the mainland East Africa can easily be evaluated. Those parts of the Jet near their source origin and yet to over-fly the upwelling Somali cold waters tend to be warm and, along their course fetch and deposit large amounts of moisture as rainfall (over 2500mm) on the Madagascar Island and South Western Indian sub-continent. 


\section{The ENSO connection: Modulations of June winds by ENSO}

Analysis of the rainfall data revealed years of 'above normal' and years of 'below normal' rainfall. Figs. 8 and 9 indicate that there are years when the rains come early and persist longer, prolonging the length of growing season, with consequent increase in amounts of received rainfall. It also shows years when rains come late and withdraw early in the season, with the bulk of the season's rains being received in few days or reduced in amount, resulting in lower amounts of rainfall and a shorter growing season. Similar observations were expressed by Stern and Coe [9] on Machakos rainfall patterns when they described them as 'Come early, go late; and 'come late go early'. Similar cycles of years of increasing rainfall and years of decreasing rainfall have been reported and are in agreement with results of Fig. $8[3,10,11]$.

Available data in the region show that during years of 'above normal rains' (for instance, 1997 El Niño) the June winds effects tend either to be suppressed, or come late in the growing season, in August after maize physiological maturity. They tend to be more prominent during La Niña years.

Fig. 8 shows that years of 'lower than normal' rainfall tend to occur in runs or in succession. This has implications on the region's soil moisture regimes and, therefore, food productivity which tends to be highly variable. The region only gets ample food production during the El Niño related seasons followed by a succession or runs of drought years (below normal rains) and, therefore, crop failures during La Niña years.

Much of the variability in East African rainfall has been linked to activities of El Niño-La Niña Southern Oscillation (ENSO) signals in Eastern Africa region, which are in turn linked to changes in sea surface temperatures (SST) of South-western Indian Ocean and the Pacific Ocean [3, 10]. The sea surface temperatures occasion pressure gradients and intense convective activities which modulate the region's wind systems, namely the North-easterlies, the South-easterlies and the East African low level Jet among others. The interactions of the wind systems with the concave configuration of the East African coastline and mainland topographic features such as the coastal ranges, Mt. Kilimanjaro, Taita, Machakos and Chulu hills, are responsible for the low amounts of precipitation received in Coastal and eastern regions of Kenya. Existence of Super, major and minor El Niños in East Africa region has been reported by Abigail et al. [7].

Investigations into seasonal rainfall variability over East Africa have revealed seasonal migration of the rainfall patterns associated with the seasonal migration of the Intertropical Convergence Zone (ITCZ). These migrations are modulated by ENSO (E1 Niño/Southern oscillation) [10]. Since the East African low level jet core coincides and moves along the zone of convergence between south-easterly and north-easterly trade winds (ITCZ), then any shifts in the path of the ITCZ due to ENSO modulations also shifts the course of the Jet stream more inland or away from the mainland [1]. This perhaps explains the absence of the June winds and their effects in the region during El Niño years, with more rains being recorded. Indeed the East African low level Jet remains active in the south-western Indian Ocean throughout the year and

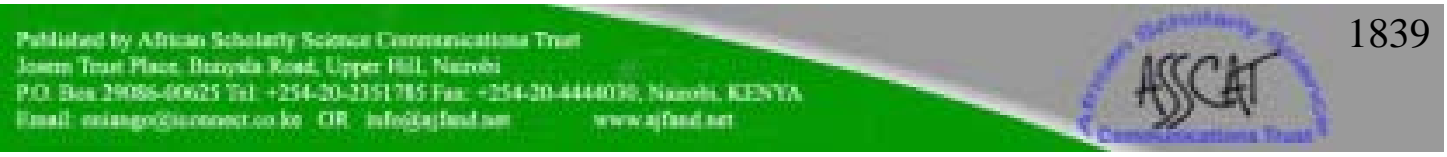


only manages to penetrate through the mainland coastal ranges into the eastern plateau when the Jet velocities are strong enough (Fig.7).

\section{CONCLUSION}

The occurrence of June winds affects prevailing weather, namely rain and ambient temperatures and soil moisture. They 'chase away' rains by creating cloud free conditions adversely affecting the amount of rains received and soil moisture for crop growth, and also by their high velocities, enhance excessive evapo-transpiration thereby aggravating soil water deficit. These effects can be summarized as:-

1) The weather during June winds 1-2 weeks occurrence during the long rains growing season tends to be excessively windy, moderately hot/cool and dry;

2) Rainfall probability decreases and the growing season shortens or is split midway.

\section{RECOMMENDATIONS}

The June winds that cause a decrease in rainfall amounts or split the growing season have severe implications for soil moisture availability for annual crops. It calls for adoption of technologies and measures that ameliorate the effects of high temperature and high velocity winds, to counter decreased moisture availability especially during critical stages of maize growth and to stabilize crop yields in the region. Their strong link to La Niña years and, therefore, droughts and also to ENSO activities presents a good opportunity in gauging their severity on expected crop yields. Since the frequency and characteristics of La Niña drought years occur in runs and can be fairly predicted with some certainty, relevant trainings need be conducted to increase awareness about the behavior of the rainfall and wind patterns on how they affect their yields, livelihoods and improve in decision making and rationalizing input, resource use and allocation, and marketing in agriculture. 
Table 1:Mean monthly rainfall and Potential evapo-transpiration (Eo) for Malindi

\section{Long rains season Short rains season}

Months Jan Feb Mar Apr May June July Aug Sept Oct Nov Dec Total

Mean

monthly

rainfall

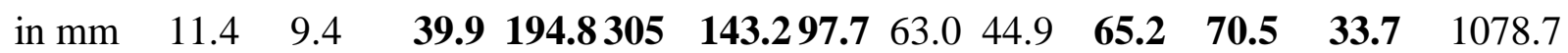

Eo in

$\begin{array}{llllllllllllll}\mathrm{mm} & 210 & 197 & \mathbf{2 1 5} & \mathbf{1 8 6} & \mathbf{1 7 1} & \mathbf{1 5 6} & \mathbf{1 5 6} & 175 & 191 & \mathbf{2 0 2} & \mathbf{1 9 5} & \mathbf{2 0 5} & 2259\end{array}$

Net

moisture

regime $\quad-198.6-187.6$-175 $\underline{\mathbf{8 . 8}} \underline{\mathbf{1 3 4}} \mathbf{- 1 2 . 8} \mathbf{- 5 8 . 3}-112$-146.1 -136.8 -124.5 -171.3 - 1180.2 
Table 2:Malindi rainfall, depicting 'Ganges' type-of-depressions on rainfall amounts due to June winds occurrence

\begin{tabular}{|c|c|c|c|c|c|c|c|c|c|}
\hline \multicolumn{10}{|c|}{ Long rains season } \\
\hline YEAR & Jan & Feb & March & April & May & June & July & Aug & Sept \\
\hline 1970 & 11 & 0 & 74 & 218 & 337 & 42 & 73 & 46 & 10 \\
\hline 1971 & 0 & 0 & 43 & 97 & 360 & 325 & 119 & 23 & 48 \\
\hline 1972 & 14 & 85 & 6 & 34 & 394 & $\underline{14}$ & 114 & 58 & 108 \\
\hline 1973 & 0 & 0 & 19 & 276 & 301 & $\overline{268}$ & $\underline{11}$ & 108 & 11 \\
\hline 1974 & 2 & 0 & 2 & 119 & 143 & 148 & 212 & 11 & 1 \\
\hline 1975 & 0 & 0 & 10 & 136 & 312 & 165 & 141 & 23 & 19 \\
\hline 1976 & 3 & 0 & 11 & 171 & 274 & $\underline{117}$ & 120 & 41 & 156 \\
\hline 1977 & 1 & 0 & 10 & 157 & 131 & 96 & $\underline{22}$ & 151 & 40 \\
\hline 1978 & 7 & 1 & 130 & 197 & 456 & 108 & 47 & 29 & 12 \\
\hline 1979 & 45 & 6 & 59 & 77 & 442 & 245 & 194 & 36 & 49 \\
\hline 1980 & 0 & 3 & 6 & 32 & 68 & 109 & 129 & 205 & 34 \\
\hline 1981 & 6 & 0 & 275 & 87 & 220 & 123 & $\underline{60}$ & 71 & 48 \\
\hline 1982 & 2 & 1 & 79 & 185 & 181 & 158 & $\overline{158}$ & 20 & 49 \\
\hline 1983 & 0 & 4 & 9 & 123 & 456 & 217 & 127 & 37 & 63 \\
\hline 1984 & 1 & 0 & 11 & 242 & 320 & 231 & 172 & 24 & 33 \\
\hline 1985 & 0 & 0 & 0 & 0 & 0 & 0 & 0 & 0 & 0 \\
\hline 1986 & 8 & 0 & 26 & 243 & 576 & 32 & 36 & 45 & 26 \\
\hline 1987 & 5 & 1 & 0 & 146 & 263 & $\underline{104}$ & 151 & 17 & 40 \\
\hline 1988 & 2 & 2 & 39 & 112 & $\underline{94}$ & 174 & 30 & 43 & 57 \\
\hline 1989 & 0 & 0 & 13 & 188 & 184 & 217 & 118 & 45 & 31 \\
\hline 1990 & 7 & 3 & 38 & 130 & 226 & 69 & 38 & 15 & 56 \\
\hline 1991 & 0 & 1 & 45 & 70 & 468 & $\underline{128}$ & 159 & 43 & 18 \\
\hline 1992 & 1 & 0 & 2 & 81 & 242 & $\underline{113}$ & 145 & 39 & 37 \\
\hline 1993 & 91 & 0 & 26 & 129 & 203 & 263 & 58 & 33 & 19 \\
\hline 1994 & 0 & 0 & 0 & 249 & 510 & $\underline{42}$ & 169 & 64 & 100 \\
\hline 1995 & 4 & 0 & 29 & 96 & 245 & $\underline{8}$ & 95 & 51 & 18 \\
\hline 1996 & 2 & 10 & 50 & 177 & 374 & $\underline{75}$ & 93 & 14 & 32 \\
\hline 1997 & 0 & 0 & 24 & 275 & 357 & 207 & 203 & 14 & 85 \\
\hline 1998 & 91 & 55 & 29 & 430 & $\underline{232}$ & 269 & 66 & 33 & 18 \\
\hline 1999 & 7 & 0 & 16 & 304 & 317 & 121 & 150 & 109 & 81 \\
\hline 2000 & 0 & 0 & 118 & $\underline{35}$ & 354 & 192 & 63 & 39 & 31 \\
\hline
\end{tabular}

(Source: Meteorological weather station, Malindi)

Note: Figures in BOLD and italic indicate long rains season amounts. Figures underlined and bold show reduced amounts due to June winds occurrence 
Table 3:Rainfall depressions by June winds in other weather recording stations of Coastal Kenya

\begin{tabular}{|c|c|c|c|c|c|c|c|c|c|}
\hline \multicolumn{3}{|l|}{ Year/stations } & \multicolumn{7}{|c|}{ Months of Long rains season } \\
\hline 1972 & JAN & FEB & MAR & APR & MAY & JUN & JUL & $A \cup G$ & SEP \\
\hline Malindi & 0.0 & 82.0 & 10.0 & 20.0 & 381.0 & $\underline{6.0}$ & 98.0 & 18.0 & 88.0 \\
\hline Gede & 30.0 & 65.0 & 3.0 & 58.0 & 286.0 & $\underline{0.0}$ & 113.0 & 13.0 & 129.0 \\
\hline KambeRibe & 95.0 & 10.0 & 55.0 & 59.0 & 361.0 & $\underline{2.0}$ & 11.0 & 60.0 & 193.0 \\
\hline Jibana & 63.0 & 8.0 & 13.0 & 37.0 & 390.0 & $\underline{113.0}$ & 119.0 & 54.0 & 170.0 \\
\hline Rabai & 56.0 & 16.0 & 10.0 & 2.0 & 474.0 & $\underline{0.0}$ & 106.0 & 73.0 & 193.0 \\
\hline Kaloleni & 63.0 & 18.0 & 36.0 & 24.0 & 296.0 & 4.0 & 70.0 & 172.0 & 172.0 \\
\hline Bamba & 32.0 & 29.0 & 43.0 & 13.0 & 140.0 & $\underline{0.0}$ & 46.0 & 59.0 & 140.0 \\
\hline Ganze & 61.0 & 13.0 & 11.0 & 12.0 & 203.0 & $\underline{0.0}$ & 23.0 & 76.0 & 97.0 \\
\hline Chonyi & 0.0 & 14.0 & 14.0 & 15.0 & 248.0 & $\underline{7.0}$ & 105.0 & 78.0 & 145.0 \\
\hline Ruruma & 74.0 & 0.0 & 6.0 & 13.0 & 411.0 & $\underline{4.0}$ & 97.0 & 81.0 & 218.0 \\
\hline Vitengeni & 36.0 & 11.0 & 41.0 & 22.0 & 164.0 & $\underline{0.0}$ & 33.0 & 55.0 & 135.0 \\
\hline \multicolumn{10}{|l|}{1973} \\
\hline Kibarani & 0.0 & 13.0 & 0.0 & 256.0 & 275.0 & 191.0 & $\underline{41.0}$ & 97.0 & 5.0 \\
\hline Mtwapa & 1.0 & 16.0 & 0.0 & 401.0 & 513.0 & 191.0 & $\underline{24.0}$ & 155.0 & 25.0 \\
\hline Malindi & 0.0 & 0.0 & 9.0 & 260.0 & 277.0 & 217.0 & $\underline{1.0}$ & 125.0 & 0.0 \\
\hline Gede & 0.0 & 0.0 & 30.0 & 84.0 & 401.0 & 200.0 & $\underline{5.0}$ & 110.0 & 14.0 \\
\hline Mariakani & 0.0 & 5.0 & 15.0 & 119.0 & 207.0 & 113.0 & $\underline{21.0}$ & 60.0 & 8.0 \\
\hline Kaloleni & 11.0 & 0.0 & 5.0 & 48.0 & 232.0 & 45.0 & 41.0 & 50.0 & 0.0 \\
\hline Bamba & 15.0 & 10.0 & 34.0 & 49.0 & 125.0 & 63.0 & 17.0 & 24.0 & 2.0 \\
\hline Magarini & 0.0 & 0.0 & 0.0 & 205.0 & 231.0 & 74.0 & $\underline{0.0}$ & 70.0 & 9.0 \\
\hline Jilore & 11.0 & 0.0 & 4.0 & 48.0 & 232.0 & 44.0 & $\underline{4.0}$ & 21.0 & 11.0 \\
\hline \multicolumn{10}{|l|}{1983} \\
\hline Mariakani & 0.0 & 5.0 & 0.0 & 35.0 & 328.0 & $\underline{0.0}$ & 76.0 & 0.0 & 0.0 \\
\hline Bamba & 0.0 & 12.0 & 0.0 & 24.0 & 132.0 & $\underline{63.0}$ & 65.0 & 35.0 & 58.0 \\
\hline \multicolumn{10}{|l|}{1984} \\
\hline KambeRibe & 0.0 & 0.0 & 0.0 & 0.0 & 227.0 & $\underline{26.0}$ & 220.0 & 266.0 & 11.0 \\
\hline Rabai & 0.0 & 0.0 & 0.0 & 0.0 & 124.0 & $\underline{109.0}$ & 134.0 & 60.0 & 14.0 \\
\hline Mariakani & 0.0 & 0.0 & 0.0 & 0.0 & 26.0 & 130.0 & $\underline{30.0}$ & 42.0 & 0.0 \\
\hline Kaloleni & 0.0 & 0.0 & 0.0 & 225.0 & $\underline{133.0}$ & 225.0 & 214.0 & 110.0 & 2.0 \\
\hline Sokoke & 0.0 & 0.0 & 0.0 & 108.0 & 101.0 & $\underline{0.0}$ & 118.0 & 4.0 & 0.0 \\
\hline Kauma & 0.0 & 0.0 & 0.0 & 303.0 & 153.0 & $\underline{74.0}$ & 90.0 & 3.0 & 15.0 \\
\hline Vitengeni & 0.0 & 0.0 & 0.0 & 61.0 & $\underline{0.0}$ & 94.0 & 75.0 & 5.0 & 4.0 \\
\hline
\end{tabular}




\section{REFERENCES}

1. McGregor $\mathbf{G} \mathbf{R}$ and $\mathbf{S}$ Nieuwolt Tropical climatology. John Wiley $2^{\text {nd }}$ Ed, 1998.

2. Semazzi HFM and M Indeje Inter seasonal variability of the ENSO rainfall signal over Africa. Journal of African Meteorological Society 1999; 3: 19-33.

3. Indeje M, Semazzi FM and LJ Ogallo ENSO signals in East African rainfall seasons. International Journal of Climatology 2000; 20: 19-46.

4. Jaetzold R and H Schmildt Farm management Handbook of Kenya, Vol. 2: Natural conditions and farm management information. Part IIc. East Africa, 1983.

5. Nicholson SE and JC Selato The Influence of La Niña on African rainfall. International Journal of Climatology 2000; 20: 1761-1776.

6. UNEP. United Nations Environmental programmes. The El Niño Phenomena. UNEP/GEMS Environmental library No. 8, 1992.

7. Abigail AA, Shrikant $\mathbf{J}$ and $\mathbf{R}$ Cynthia Spatio-temporal effects of El Niño events on rainfall and maize yield in Kenya. International Journal of Climatology 2000; 22: (15) 1849 - 1860.

8. Findlater $\mathbf{J}$ The low level cross equatorial air current of the western Indian Ocean during the northern summer. Weather, 1974; 29: 411-16.

9. Stern RD and $\mathbf{R}$ Coe The use of rainfall models in Agricultural planning. Agricultural Meteorology, 1982; 26: 35-43.

10. Ogallo L Rainfall variability in Africa. Monthly Weather Review 1979; 107: 1133-9.

11. Tiffen M, Mortimore $\mathbf{M}$ and $\mathbf{F}$ Gichuki More people, less erosion, environmental recovery in Kenya. John and Wiley Chichester. 1994; 311p. 